\title{
Analysis on the Cultivation Mode of Innovative Talents for Automotive Engineering
}

\author{
Renhua Yang \\ School of Automotive and Traffic \\ Xihua University \\ Chengdu Sichuan 610039
}

\begin{abstract}
This paper analyzes the current situation and problems of talents cultivation for automotive engineering. By discussing the basic path to cultivate innovative talents for automotive engineering, this paper puts forward the cultivation mode of innovative talents which is of great significance to the cultivation of innovation talents for automotive engine ering.
\end{abstract}

Keywords-practical teaching, reform, cultivation mode, innovation

\section{INTRODUCTION}

In the end of last century, UNESCO pointed out in publicly-issued Policy Document of Educational Reform and Development that "nowadays, the quality of talents cultivation is one of three global issues of education in 21st century ". Education should respond to the changing world with targeted, high quality and international characteristics. The automotive engineering major develop very fast over the past ten years. At present, there are over 100 domestic institutions of higher learning to offer this major such as Jilin University, Tsinghua University, etc. Students can learn basic theories and skills of automobile design, be familiar with mechanical technique, electronic technology and computer technology, conduct scientific experiments and train their scientific thinking. Each college has different talents cultivation mode, but their construction in this major is developing and improving. The cultivation of innovative talents is the cornerstone of national economic development and the power source of thoughts to lead social progress. In addition, it also the priority for colleges. This paper takes the construction of automotive engineering in Xihua University as an example to analyze the talents cultivation mode for automotive engineering based on innovative talents cultivation.

\section{THE CURRENT SITUATION OF TALENTS CULTIVATION MODE FOR AUTOMOTIVE ENGINEERING}

Western developed countries pay much more attention to abilities and the potential of research and innovation in institutions of higher learning. In the aspect of teaching system, our country sets a high bar for the college entrance examination while makes it very easy to graduate from college, which is the opposite situation for foreign countries. Comparatively speaking, it is the latter situation that is more conducive to cultivate talents. In the aspect of schooling system, it is relatively fixed in our country but flexible in foreign countries. Foreign education attaches great importance to students. In the aspect of educational management system, the domestic education orients toward administration while foreign education is relatively independent. Only minimizing administrative restriction can institutions of higher learning create sound environment for cultivating talents. In a word, we should learn as well as make full use of the essence of the cultivation mode system of innovative talents from foreign institutions of higher learning. In the meantime, we should combine with Chinese characteristics to establish a set of innovation talents cultivation mode in institutions of higher learning suited to our economic development, which is the top priority for higher educational work. However, there are lack of the combination of qualitative and quantitative research on the existing mode. In the past, scholars always researched in a superficial way, which means that they focused on qualitative research and lacked quantitative analysis and resolution on innovative talents cultivation mode for institutions of higher learning. How to promote related researches and policy measures concerning the sound transformation of innovative talents cultivation in our institutions of higher learning is the most urgent requirement for today's social and economic development. In our country, the research on innovative talents cultivation mode for higher education begins very late. It was since 1990s that related theories about innovative talents cultivation mode began to be introduced into our country. Compared with higher education in developed countries, there are many factors restricting the education of innovative talents cultivation in institutions of higher learning in our country, among which the most critical factors are that the higher education cannot meet social need in terms of number, existing enrollment system has disadvantages, higher education does not orient toward policies and the talents cultivation mode in institutions of higher learning is still the traditional one. Thus, it is urgent to develop the talents cultivation mode suited to social and current development in the lights of the times. At present, over 100 colleges have the major of automotive engineering. Although there are differences in cultivation mode among various college, there exists some common problems in institutions of higher learning in China[1].

\section{REFORM ON THE CONCEPT AND OBJECTIVE OF TALENTS} CULTIVATION MODE FOR AUTOMOTIVE ENGINEERING

\section{A. Concept}

It should stick to such concept as "lays a solid foundation, emphasizes quality, strengthens abilities and orients toward 
enterprises" and center on the cultivation of innovative talents for automotive engineering. Additionally, it should enhance humanistic quality education, intensify the cultivation of the ability in creative thinking and practice, reinforce the integration of basic courses, strengthen research training and promote the integration of educational industry and colleges.

\section{B. Cultivation objective}

It should cultivate higher level innovative talents for automotive engineering who have sound humanistic quality, solid basic theoretical foundation, adept skills, correct way of thinking on automotive design, proficient in automotive testing and experimental techniques and the potential to guide industry and creative design.

\section{REFORM OF TALENTS CULTIVATION MODE FOR AUTOMOTIVE ENGINEERING}

Aiming at the current situation of talents cultivation for automotive engineering and in accordance with established cultivation concept and objective for automotive engineering, we can cultivate innovative talents for automotive engineering from the following aspects:

\section{A. Stimulating students' enthusiasm and initiative of learning}

The impetus for undergraduates to insist on studying four years is to make them get to know and love their majors, cultivate their interests, sense of responsibility and active learning spirit and understand their majors in a correct and overall way. As a matter of fact, the desire to have deep understanding on the major goes through from the very beginning of applying for colleges to their enrollment and to their graduation. Most students know their majors in an unaware, natural and spontaneous manner, thus this process is relatively slow and tends to arise deviations. Therefore, we believe that it is necessary to advertise majors and guide the work as soon as they enter the colleges.

As soon as students enroll in colleges, the director of teaching and research center can introduce the cultivation objectives, teaching contents, the characteristics of the major as well as the development and construction of automotive engineering in Xihua University and job orientation for this major to freshmen. And then they can take a tour of research institutions and related laboratories to get to know research projects. And related teachers should answer their questions with demonstration and explanation in order to make students know the connotation of their majors, encourage them to enter the laboratories to research and further study for degrees, thus clarifying their study objectives and strengthening their interests and initiative.

The instruction on students' study by professional teachers should be standardized through the management system of counselors and professional tutors. And every professional teachers can take their due responsibility to help student build correct direction for their majors. It should arrange excellent young teachers with stronger research ability to be the tutors of classes and invite the most influential teachers in this major on a regular basis to do special report and research presentations for students[2].

\section{B. Relying on strong disciplines, the discipline construction and development can be driven by major construction and undergraduate education}

It should take into account both the planning of the majors for undergraduates and disciplinary planning. The specific guidance on cultivation objective, curriculum system, courses, the construction of laboratory and allocation of teachers should be put forward. And it should have overall consideration on the teaching for undergraduate and postgraduate, especially the connections between the courses of undergraduate and postgraduate.

The long effort teachers put in research and frequently-used equipment have freely been transferred to the teaching for undergraduate.

The rapid development of disciplines has made a bright prospect for future employment, which stimulates students' enthusiasm of learning. The diversified disciplines provide postgraduates with lots of options to choose courses, which creates a sound situation for students to further study and becomes one of the best ways for undergraduate to continue their study.

Relying on the disciplinary construction of mechanical engineering, the development and construction of automotive engineering can be stimulated to develop. In addition, we should provide a good source of research for high quality undergraduates.

\section{Curriculum system and teaching content}

According to the concept and objective of the cultivation of innovative talents for automotive engineering, it should reform curriculum system and teaching content, strengthen the ability of professional practice and the construction of humanistic courses, offer integrated basic courses, specialty basic courses, specialty comprehensive courses, practice courses and humanistic courses and emphasize the development of courses with special characteristics. In addition, the research training should be included in the whole process of teaching. It should also strengthen basic theoretical knowledge and quality education and emphasize practical teaching to further promote students' individual development and intensify their ability in independent study and lifelong learning[3].

\section{Focusing on the part of practical teaching}

Students' creativity doesn't come from nowhere. As for those who engage in natural science and engineering technology, sound experimental teaching and environment are the basic condition for stimulating and promoting creative thinking.

It should make full use of existing disciplinary platform jointly-built with local government in order to provide sound creative experimental condition for undergraduates. It should actively strive for a special fund from central finance to support the development of local institutions of higher learning and the construction of professional laboratories.

It should actively conduct the cooperation among industries, colleges and research institutions to widen the channels of 
practice for students, strive for the support of society and enterprises to jointly build laboratories and cooperate with competitive enterprises in order to create better practical condition for cultivating world-class talents of automotive engineering.

In addition, it should actively transform research achievements into undergraduate specialized experimental projects and drive the development of experimental teaching under the promotion of researches. What's more, it should give full play to the role of graduates in the construction of laboratories. They can not only take part in the work of testing equipment and preparation, but also be the assistants of experimental teaching to guide students how to operate experiments. And they are quick learner at new things with strong practical ability and good at imparting knowledge to undergraduates which can make undergraduates accept easily, thus guaranteeing the effect of teaching.

\section{E. Teaching methods and means}

It should conduct reform on educational methods and teaching methods for the purpose of developing studentcentered teaching and improving independent study. Additionally, it should teach in both Chinese and English or in English in small class. It should integrate such teaching mode as heuristic method, method of discussion and research into teaching to improve students' ability in independent study. Furthermore, it should widely adopt various modern teaching methods and means to improve teaching effect[4].

\section{F. Emphasizing that graduation projects must be from scientific research and engineering practice}

Graduation project is the most important part for students to re-study and improve their ability in application of knowledge and solving problems independently. The way to strengthen the source of projects of students majoring in automotive engineering lies in research projects and engineering practice, including various assemblies of automobile, assemblies of electronics and electronic appliance and some auxiliary assemblies.

\section{G. Ways of evaluation and assessment}

The assessment system which combines process evaluation with final evaluation should be built. In different learning stage, comprehensive examination on courses knowledge should be implemented in order to evaluate students' ability in mastering and applying basic knowledge. It should observe students' theoretical learning and practice from the very beginning to the end and offer personalized assessment.

\section{H. Promotion the talents cultivation driven by engineering application and scientific research}

In a group of research project, most researchers are postgraduates. It should attract excellent undergraduates to join in. They can directly take part in projects application, project demonstration, implementation, tackling and identifying key technological issues, etc. And they can accept training in academic morality, research ability and organizational ability. Thus, some outstanding students can start their researches on some important issues in undergraduate stage, continue the rest researches in postgraduate and then make achievements.

\section{Focusing on the training of research}

Depending on provincial key disciplines and laboratories, national demonstration center of experimental teaching and innovative experimental projects for college students, students can acquaint themselves with scientific research and receive research training since the third semester by "three joins" (join in research projects, platform and groups). In junior and senior year, courses about research training will be offered in order to further enhance their ability in research. In the meantime, under one on one guidance of mentors, their ability in research will be improved through special research projects.

\section{J. Taking the cultivation of innovative talents as its core to innovate teachers' educational mode, implement the plan of research training for college students in an all-round manner and build quality and ability-oriented cultivation system of innovative talents}

1) Innovating teachers' cultivation mode to guide their educational development. It should further advance the exploration and practice of cultivation mode for future excellent teachers and aim to cultivate the teachers who are happy and suitable to teach and good at teaching. It should improve the educational and curriculum system, perfect integrated practical teaching system composed of experiencebased educational probation, research project-driven educational training and practice-oriented internship and deal well with the evaluation on process and quality tracking for the cultivation of undergraduates. In addition, it should promote the construction of practical center for teachers' education and teaching in order to build an important base and platform for the cultivation of practical teaching ability.

2) Promoting innovative culture in colleges and implementing the plan of research training. It should respect personality, display specialties, stimulate exploration, encourage cooperation and tolerate unsuccessful innovative culture in colleges. Moreover, it should base on the cultivation of students' innovative awareness and thinking to carry out the plan of research training for college students in an all-round manner. It should make full use of research bases and scientific and technological activity base for undergraduates outside class to include research training into teaching and attach importance to the basic experience of students who engage in research training.

\section{K. Building a well-constructed excellent professional teaching team with both full-time and part-time faculty}

Firstly, relying on teaching and research platform, it should build a teaching team centering on middle-aged and young backbone teachers with the disciplinary, curriculum and major construction as its core in order to have coordinated and integrated development among the construction of disciplines, majors, research, curriculum and teaching and promote the overall enhancement of teachers' quality. Secondly, it should not be restricted to single mode of course design. It should develop integrated courses of basic knowledge, build teaching 
teams and promote students' innovative study in accordance with the concept of course integration. Thirdly, while introducing and cultivating high-level and high-quality leaders of the majors and backbone teachers, it should make full use of the faculty advantages of local key enterprises; employ experts with strong teaching ability as part-time teachers and some domestic and foreign experts and scholars to take part in teaching. Fourthly, it should build an outstanding practical teaching team and in particular employ excellent engineering technicians from enterprises to participate in practical teaching in order to promote the interaction between theory and practice and between teaching and research and enhance teachers' teaching ability, thus further strengthening their enthusiasm on taking part in practical teaching[5].

\section{CONCLUSION}

It is a long-term and complicated systematic project to build the major of automotive engineering and cultivate talents. How to cultivate the talents that automotive industry really needs is an important issue for every workers in higher education related to this major, which requires us to think and research. It is the top priority for educational community to explore scientific and practical mode to cultivate talents. It should build such innovative talents cultivation mode for automotive industry as bases on ability and emphasize the cultivation of students' comprehensive abilities, which will necessarily cultivate more and better automotive technical talents for our society.

\section{REFERENCES}

[1] Cai Zhidan, On Exploration and Practice of Innovative Talents Cultivation Mode in Institutions of Higher Learning[J]. Asia-Pacific Education, 2016(5)

[2] Xia Meijuan, et al, Teaching Reform and Practice of Automation Majors Based on Innovative Talent Cultivation Mode[J]. Jiangsu Science\& Technology Information, 2018 (2)

[3] Chen Lihua, et al, Exploration and Practice on the Model of Cultivating Innovative Skills Oriented Programs for Medical Laboratory Technology Discipline[J].China Higher Medical Education, 2017(4)

[4] Guo Yong, et al, Exploration on Teaching Mode of Dairy Microbiology Course in Vocational Colleges Based on the Talents Cultivation Mode of "1+1+1" of Colleges, Research Institutions and Enterprises[J]. Heilongjiang Scientific and Technological Innovation, 2014(31)

[5] An Jiangying, et al, Analysis on the Construction of Cultivation Mode for High-End, Skillful and Innovative Talent[J]. Way of Success, 2015(22). 